\title{
Research and Analysis for Development Status of Rural Informatization in China ${ }^{1}$
}

\author{
Wenqiu Ma ${ }^{1,}$, , Xiu Wang ${ }^{2, b^{*}}$ \\ ${ }^{1}$ College of Public Administration, Nanjing Agricultural University, Nanjing 210095, China \\ ${ }^{2}$ Beijing Research Center for Information Technology in Agriculture, Beijing Academy of Agriculture \\ and Forestry Sciences, Beijing 100097, China \\ a email: qiuliang91927@163.com, ${ }^{b}$ email: xiuwang@263.net
}

Key words: Rural informatization; development status; policy suggestions

\begin{abstract}
Rural informatization as the crucial part of urban and rural harmonious development, it has important significance to accelerate the agricultural modernization construction, and to build a new socialist countryside. Combining with current status of rural informatization, this research tries to analyze its content, achievement and problems, etc. On the basic of this study, the article puts forwards policy suggestions to promote development of rural informatization.
\end{abstract}

\section{Introduction}

In 2005 Central NO.1 Document, the Party Central Committee puts forwards some issues about rural informatization, pointing out: "Accelerate the research process of biological technology and information technology", and "Strengthen the construction of rural informatization". After then, the definition of rural informatization has been repeated in Central NO.1 Documents in the following years. Seventeenth National Congress of the Communist Party of China states:” The goal is to strengthen the agricultural construction of infrastructure, open a trail with agricultural modernization Chinese characteristics, build a mechanism of "promoting agriculture with industry " and " quickening the development of townships under the leadership of cities ", and form a new pattern of the integration of urban and rural economy and social development." It is not only a significant strategy of promoting urban and rural harmonious development, based on fundamental realities of the country, but also a scheduled task of building a well-off society in an all-round way. As a key content and necessary foundation, accelerating the construction of rural informatization has fundamental, strategic and leading influence on promoting integration of urban and rural development. Therefore, rural informatization should be impelled because of a great strategy for urban and rural harmonious development.

\section{Content of Rural Informatization}

Recently, from different aspects, several scholars have discussed the content of rural informatization. Some of them define it from the aspect of rural information technology, who think that rural informatization should include agricultural production management informatization, agricultural science and technology informatization, agricultural operating management informatization, agricultural market circulation informatization, agricultural resource informatization and agricultural consumption informatization, etc ${ }^{[1]}$. Some of scholars define it from the aspect of rural information infrastructure, who think that rural informatization is the whole process of rural fundamental geology and functional digitization, network and visual intellectualization, etc. And some of them define it from the aspect of rural information resource, who think that rural informatization is the application of information technology, deep exploration and wide utilization technique resource, in order to realize process of rural modernization ${ }^{2]}$. All in

\footnotetext{
${ }^{1}$ The study is supported by National Key Technology Research and Development Program of the Ministry of Science and Technology of China (2011BAD21B02)

Corresponding author: Xiu Wang
} 
all, in accordance with the China's development practice of rural informatization, Guo(2007) redefine it as a process that can accelerate the developing level of rural information technology and industrialization, explore all kinds of agricultural technology resource, increase level of application in rural economy and promote the mechanism of rural economy, social organizational form and lifestyle advance, thus improving the advance of social development.

\section{Current Status}

Achievement World Bank Group stated: “Over the last decade, informatization - the transformation of an economy and society through the effective deployment of information and communications technologies in business, social and public functions - has been a significant phenomenon in China." In the view of history course of rural informatization in China, informatization starts relatively later in countryside. Ministry of agriculture didn't pay attention to experiments and application of computer science until 1987. In the 11th Five Year Plan, national rural informatization development has gained great achievement that rural informatization infrastructure has been rapid popularization. And until late 2010, the index of rural informatization has been 0.35 increasing by one time compared with 0.19 in 2005. Within the period of 11th Five Year Plan, the project of "Communication with Every Village" realizes the leap from telephone to informatization, which not only has impact on increasing farmers' income, promoting rural social undertaking development and enriching farmers' cultural life, but also provides rural informatization construction of infrastructure ${ }^{[3]}$.

"Communication with Every Village" Project promotes construction of rural informatization infrastructure: In recent time, with the painstaking of central and local governments, rural informatization construction has obtained great progress. For instance, with the leading of "Communication with Every Village" Project, the number of broadband users in China has grown rapidly in recent years. According to data from the China Internet Network Information Center, the scale of rural Internet users reaches to 136 million RMB, which accounts for 26.5\% among whole Internet users- lagging behind the United States by just 5 million RMB. Besides, central government has invested 150 million RMB to install fixed line telephone, which will launch in 2008 and is expected to be completed in three to five years. Today 99.5 percent of administrative villages in China have fixed line coverage ${ }^{[4]}$.

Agricultural Database enriches agricultural information resource: With the construction of Information Superhighway, there are all kinds of databases whose information service function has been gradually improved being built. Agricultural database is similar with these national databases, which presents a tendency of large sales volume, rich information and standardization of information processing. Except for some native database system like VIP, National Agricultural Sci-Tech, various foreign databases have been introduced into agricultural application such as AGRIS, IFIS, AGRI-COLA, CAB1 and Taylor\&Francis, etc. These international databases provide a large number of international agricultural information resource, meanwhile, they also promote the progress of Chinese database.

Perfect law system ensures rural informatization regular development: China has identified rural informatization as a key to achieving nationwide growth and improving people's capacity for participating in new economic domains. 2007 Central NO.1 Document about "Developing modern agriculture to promote new socialist countryside construction" has made a successful start of modern agriculture, and a series of policy measures accompanied with new countryside construction have been unveiled in succession, especially some policies of rural informatization such as the State Informatization Development Strategy, 2006-2020 underscore the importance the government has accorded to rural informatization. The nation and some relative ministries have established several management methods to regulate construction of rural informatization and to enhance capability of information service.

Existing Problems Although the information in rural areas in the country has achieved great development in recent years, informatization still cannot meet the growing information needs of farmers. With the restriction on location, economy and perception, China's rural informatization 
still lies in primary stage. Besides, compared with some developed countries, there is growing gap between developing and developed countries. And the development between different regions is unbalanced in China.

A lack of subject of rural informatization makes unawareness of information technology in rural areas: In China, countryside has distributed in counties, where leaders in these regions mainly focus on agricultural production and farmers' income increase, while they don't take rural construction seriously. Governments don't play important roles in construction of rural informatization and their level of value also need to enhance. In traditional structure, supply of public goods usually adopts two systems: urban public goods depend on national financial investment; rural public goods depend on farmers' building investment. Obviously, traditional supply system cannot meet construction of rural informatization needs. Farmers just are the demand subjects, but cannot be supply subjects of rural informatization.

Low frequency of information resource impedes rural informatization integration and share: According to insufficient information about macro-control and production management decision, especially for the government's imperfect information collected channels and little information source, etc. There are more accessible information in nation than that in internation, more consequential information than predicable information and more productive information than market information. Multi-direction investigation of government departments causes some consequences like a lack of planning and coordination, social institution dispersion and low information sharing rate.

Imperfect information security service system contributes to poor capability information service: There are some universal phenomena for basic agricultural information service such as uncompleted organizations, poor capability of effective supply, deficient service talents and so on. Only 19\% national Internet information service is in countryside, and the rate of families who can obtain market information through Internet just is $0.8 \%$. There exist some conflicts of interests among governments, farmer organizations and enterprises, which are main causes of unsustainable information service work.

Distinction of developing level of informatization between different areas leads to a significant urban-rural and home-abroad information gap: At present, the development of rural informatization has come into industrialized period in some western countries. Some advanced technology like computer science, communication and artificial intelligence has been utilized into agricultural production ${ }^{[5]}$. However, it is necessary to enhance whole informatization power in China. Although information construction in rural areas has achieved some success, it has not yet formed a complete, practical, widely used public service information system in rural areas. The grass-roots e-government and information technology facilities such as online offices are still not complete. The data of Internet popularity rate of urban-rural users from 2005 to 2009 (Figure. 1) shows that within these years, the gap between urban and rural Internet users has been enlarged. And the index of urban-rural digital gap from 2002 to 2009 (Figure. 2) provided accurate statistics for this distinction ${ }^{[6]}$.

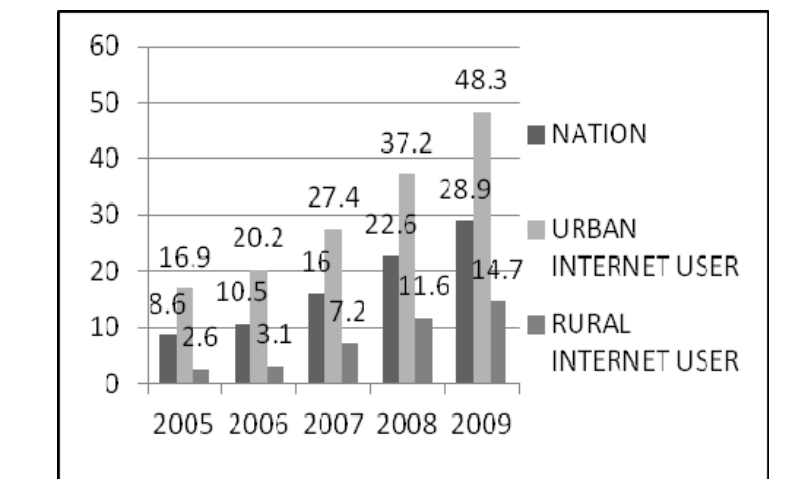

Fig. 12005 - 2009 Internet popularity rate of urban-rural users $(\%)$

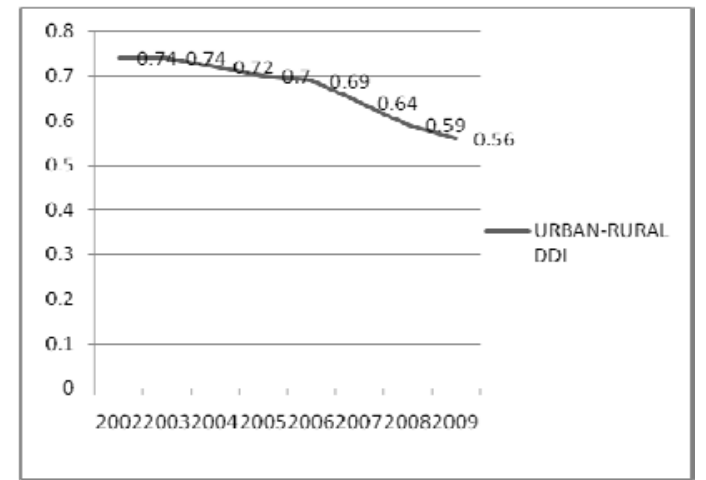

Fig. 22002 - 2009 Index of urban-rural digital gap in China 


\section{Policy Implications}

Rural informatization is the process of using modern technology to improve agricultural production capacity, rural management level, and farmers' quality of life in rural areas. Currently, developed countries have all enhanced their rural informatization process. However, taking China current status of rural informatization into consideration, the article provides following policy suggestions to improve the further development:

Enhance and Perfect Management System. Rural informatization cannot be divided by government departments. The key factor about rural informatization developing smoothly is the governmental high attention, unified planning and effective management. Local governments should use as reference the beneficial fruit of construction pattern of economic zone, transform economic structure and search for a new mechanism fit for integration of urban and rural economy, especially mobilize all positive senses of farmers.

Integrate and Share with Agriculture-related Resources. All agriculture-related organizations have built their own websites. However, considering the fact that different departments and organizations are lack of communication and coordination, which has caused the waste of resources and is not conducive to the use of resource, it is important to use the "221 information platform” to fully integrate agro-resources from both internal and external networks.

Increase the Quality and Relevance of Information and the Human Capacity of the Rural Population. Access to relevant information can transform economic opportunities and improve livelihoods for rural households - especially the poor population and young people. Rural informatization not only directly affects economic development, but it also brings in modern ideas and forward looking mindsets from more advanced regions. That can pave the way for diminishing the gap between urban and rural areas, increasing rural, social and cultural capacities in rural areas.

\section{References}

[1]Li, D: Report on China rural informatization. China Information Times, Vol. Z1(2009), p.72-84.

[2] China Focuses on Rural Informatization. I-Ways Journal of E-Government Policy and Regulation, Vol. 32(2009), p. 213-215.

[3] Carol Ting, FaminYi: ICT policy for the "socialist new countryside "-A case study of rural informatization in Guangdong, China. Telecommunications Policy, Vol.3(2012), p. 234-243.

[4]Zhang Jialin, Jiang Jinfu, Ling Lianlian. A study on rural informatization and .rural sustainable development in China. Management of Agricultural Science and Technology, Vol.1(2006), p.15-18.

[5]Tang Man, Xia Jianqun. Comparison of rural informatization between China and the United States. Library Theory and Practice, Vol. 2(2013), p. 39-43.

[6]Huang Hao. Seeking for China rural informatization and ways of realization. Sci-Tech Information Development \& Economy, Vol. 11(2006), p .72-74. 